\title{
Prevalence and determinants of dietary practices among pregnant women in eastern Ethiopia
}

\author{
Meseret Belete Fite ${ }^{1 *}$, Abera Kenay Tura ${ }^{2,3}$, Tesfaye Assebe Yadeta ${ }^{2}$, Lemessa Oljira ${ }^{4}$ and Kedir Teji Roba ${ }^{2}$
}

\begin{abstract}
Introduction: Appropriate dietary practices in pregnancy are critical to meet the increased metabolic and physiological demands; however, information about dietary practices among pregnant women, particularly rural residents, is limited. The study aimed to assess the level of appropriate dietary practices and associated determinants among pregnant women in Haramaya District, eastern Ethiopia, 2021.

Methods: A community-based cross-sectional study was conducted among 448 pregnant women in Haramaya District, Eastern Ethiopia. Data was collected through face-to-face interviews by trained research assistants, using a validated frequency questionnaire. The pregnant women were labeled as "appropriate dietary practice" when they consumed at least four meals daily, had a good food variety score, high dietary diversity score, and high consumption of animal source foods during the reference period. Otherwise, they were defined as "inappropriate." A Poisson regression model with robust variance estimation was used to investigate the association of the independent variables with the dietary practice. An adjusted prevalence ratio with a 95\% confidence interval was reported to show an association using a $p$-value $<0.05$.
\end{abstract}

Results: The appropriate dietary practice among the study participants was $15.2 \%$ (95\% Cl=12-18\%). Of the respondents, 29.46, 37.5, and $24.7 \%$ had a high dietary diversity, high food variety score, and high consumption of animal source foods. The appropriate dietary practice was more prevalent among merchant women $(\mathrm{APR}=2.07$; $95 \% \mathrm{Cl} 1.07-4.02)$ and those whose husbands have at least a high school educational level (APR $=1.96 ; 95 \% \mathrm{Cl}$ 1.06-3.46). However, the prevalence of appropriate dietary practice was significantly lower among those who chewed khat (APR $=0.58 ; 95 \% \mathrm{Cl} 0.37-0.90)$ and among respondents who reported restriction of the intake of some foods (APR $=0.36 ; 95 \% \mathrm{Cl} 0.20-0.65)$.

Conclusion: We found sup-optimal appropriate dietary practice among pregnant women in this predominantly rural setting. Additionally, the lower appropriate dietary practice was observed among women who reported chewing khat and experienced restriction of dietary consumption during pregnancy. Therefore, nutrition policy programs and interventions aimed at encouraging maternal nutritional guidance and counseling are recommended.

Keywords: Dietary practice, Dietary diversity, Food variety score, Pregnancy, Ethiopia

*Correspondence: meseretphd2014@gmail.com

1 Department of Public Health, Institute of Health Sciences, Wollega

University, Nekemte, Ethiopia

Full list of author information is available at the end of the article

\section{Background}

A healthy and balanced diet is essential for human beings to have sustainable health and appropriate working of the body [1]. During pregnancy, there are increased metabolic and physiologic demands on the body, which 
are expected to be met by adequate nutrition [2]. However, at conception, many women do not have sufficient micronutrient intake to meet their bodies' demands [3]. Therefore, this lack of specific dietary practices during pregnancy is critical for under-nutrition and micronutrient deficiencies resulting in poor birth outcomes [4]. The basis for these problematic dietary practices in unindustrialized areas include inadequate access to food sources and poor knowledge on the essence of good diet quality and quantity. Moreover, pregnant women in developing countries mainly consume a diet predominantly plantbased, macronutrient imbalanced, and consisting of inadequate micronutrients [5-8].

Accordingly, studies revealed that good diversity practices in pregnant women in low-middle income countries varied, ranging from $20 \%$ in Pakistan [9] to $70 \%$ in India [10]. However, most pregnant women in Sub-Saharan Africa have insufficient dietary consumption and do not meet the recommended dietary allowances (RDA) [11]. Likewise, evidence suggests the appropriate nutritional practices of pregnant women in Ethiopia ranged from $19.9 \%$ in Gojjam [5] to $40.1 \%$ in Gonder [6]. The researchers used various tools to evaluate the dietary practices of pregnant women; some were using nutrient content however meal frequency was the most common.

Few studies reported factors affecting maternal dietary practices in different parts of Ethiopia. For example, edible crop production, attitude, dietary knowledge [6], cultural prohibition, women's educational level, income, and ownership of livestock $[5,11]$ were documented as predictors of the appropriate dietary practices. In addition, the age of the mother, food taboo, and meal frequency was explored as determinants of the dietary practices among pregnant women [12].

We hypothesized that pregnant women in this study setup exhibit low appropriate dietary practice, and this is affected by different independent predictors. Therefore, the objective of this study, is to assess dietary practice and the determinants among pregnant women.

\section{Methods}

\section{Study settings}

The study was embedded into the Haramaya Health Demographic Surveillance and Health Research Centre (HDS-HRC), which was established in 2018. The HDSHRC located in Haramaya district. Haramaya District, located $500 \mathrm{~km}$ away from the capital city, Addis Ababa to the east. Haramaya district consists of 33 kebeles (the lowest administrative unit in Ethiopia). HDS-HRC covers 12 rural kebeles which is representative and randomly selected by considering geographic and environment issues. In HDS-HRC 2306 pregnant women were followed. The district has mixed farming, with the major cash crop being khat (Catha edulis Forsk) [13]. The study was conducted from January 5 to February 12, 2021.

\section{Study design and population}

A community based cross-sectional study was conducted. All pregnant women living in the district constituted the source population; whereas all pregnant women who lived in the selected kebeles for at least 6 months during the study period were the study population. The sample size was determined using single and double population proportion formulas with their corresponding assumption, and the largest sample was considered. However, this study is part of a larger longitudinal study which obtained birth outcome information in pregnant women; thus, the sample size which was used in this study was calculated from the larger study that included 475 pregnant women. Birth outcome (Low birthweight) was the main outcome was used in calculating the sample size. Sample size was determined from Charan and Biswas study [14].

Where, $\mathrm{n}=$ sample size, $\mathrm{Z} \alpha / 2=1.96$ at type 1 error of $5 \%, \mathrm{Z} \beta=0.84$ at $80 \%$ power, $\mathrm{P} 1=\mathrm{LBW}$ in pregnant women with no gestational HTN (22.9\%), P2=LBW in pregnant women with gestational HTN (10.37\%), p1-p2 = difference in prevalence of low birth weight between pregnant women with no gestational HTN at birth and those with gestational HTN and $\mathrm{p}=$ pooled prevalence $=(\mathrm{p} 1+\mathrm{p} 2) / 2$ [15].. A study among pregnant women in the area reported LBW prevalence of $21.0 \% \%$ (LBW DD). Hence, we proposed that LBW in pregnant women with gestational HTN would be $22.9 \%$, while those with gestational HTN would remain $10.37 \%$. Hence, $\mathrm{p} 1=22.9 \%, \mathrm{p} 2=10.37 \%$, their proportions being $\mathrm{p} 1=0.229$ and $\mathrm{p} 2=0.1037$, and $\mathrm{p}=(0.229+0.1037) / 2=$ 0.16635 .

Using the above descriptive, the sample size $n=2(1.96+0.84) 2 \times 0.16635(1-0.21) /(0.229-0.1037) 2$, $n=2.152 / 0.01$, equal 216 was calculated, which implied we needed to recruit 216 participants in each arm of the study (half in the with gestational HTN group and a half in the no gestation HTN group) making 432 participants showing a significant association between gestational HTN and LBW. Nevertheless, by adding 10\% nonresponse rate to 475 participants were included. After constructing a sampling frame from the HDS-HRC database, simple random sampling was applied to the eight randomly selected kebeles and then the eligible women were selected using computer generated lottery method.

\section{Data collection and measurement}

Data was collected through interview administered questionnaires by trained research assistants. The questionnaire contained data on socio-economic, obstetric, 
maternal perception, food consumption, dietary knowledge, attitude, and practices of pregnant women. The questionnaire was initially prepared in the English language and was translated to the local language (Afan Oromo) by an individual with good command of both languages. It was also pre-tested on $10 \%$ of the sample in Kersa District before data collection. In addition, mid-upper arm circumference (MUAC) was measured to assess nutritional status.

Four measures were used to measure the dietary practices of pregnant women including dietary diversity, food variety, animal source foods consumption, and frequency of meals. In this context, the formerly validated food frequency questionnaire (FFQ) containing 27 of the most commonly lists of food items consumed by the district community was used to assess dietary diversity of the study participants [16-20]. Additionally, this validated FFQ was used to assess dietary diversity of the participants [21, 22]. Initially, the list of food items was established based on consultation of key informants living in the study area, who knew the culture, local language, and foods typically consumed. Then the food frequency questionnaire was pretested on $10 \%$ of the sampled pregnant women in the district who were not included in the main study and necessary modifications were made based on the observations. In addition, pretested food frequency questionnaires were carried out on $10 \%$ of the sampled pregnant women of the district not included in the main study. Necessary modifications were made before actual implementation to generate data. Finally, to measure the consumption of each food per day, per week or per month for the FFQ in the past 3 months to consider the difference of dietary consumption within a day of a week to take the concept into account. However, we considered the greater difference of dietary practice in the local community over the day of the week, the intake of each food item per day $[6,23]$ was not taken as a cut-off point to label consumers. In doing so, pregnant women were defined as "consumer" of a food item if they had consumed those items at least once over a period of a week $[21,24]$.

Validity and reliability were assessed for each construct by using the common factor analysis with oblique (Promax) rotation and were censored by the use of already validated FFQ from a similar study. The reliability or internal consistency of each scale was assessed using Cronbach's alpha values as the reliability estimates and ranged from 0.67 to 0.86 . A Cronbach's alpha of 0.7 was generally considered acceptable (Nunnally, 1978). In this study, the Cronbach's alpha value was 0.76 as well as the test-retest method was used to determine the reliability of the instruments during the pretest. A test-retest correlation coefficient of 0.76 (CI: $0.61-0.82$ ) was computed from the two sets of data and found to be adequate. A value of +0.80 or greater was generally would indicate good internal consistency.

The food items in the FFQ were grouped into ten food groups. These are: cereal, white roots and tubers, pulse and legumes, nuts and seeds, dark green leafy vegetables, other vitamin A-rich fruits and vegetables, meat, fish and poultry, dairy and dairy product, egg, other vegetables, and other fruits [25]. The sum of each food group that the pregnant women consumed over a period of 1 week were calculated to analysis the dietary diversity score (DDS). Furthermore, dietary diversity score was converted into tertiles, and the highest tertile used to label "high" dietary diversity score whereas both lower tertiles combined were defined as" low" dietary diversity score. Food variety score (FVS) is the frequency of individual food items consumed in the reference period of the study. Therefore, it was estimated by the intake of 27 food items by each individual over 7 days [21],with maximum of FVS fourth. Finally, the mean FVS of pregnant women was calculated and those of them with FVS greater than the means were labeled as having "high" food variety score whereas those with FVS lower than the means were defined as having "low" FVS. Furthermore, consumption of foods from animal source (ASF) was estimated by counting the frequency of each food from animal sources that pregnant women ate over a reference period. Animal source foods score was also converted into terciles and the highest tercile used to label as "highs, while the two lower terciles combined were defined as "low" ASF.

\section{Data quality assurance}

Two days of rigorous and extensive training with the final version of the questionnaires was given to each data collector and supervisor prior to pre-test. Collected data was checked by supervisors before being sent to the data entrée on daily basis. We pre-tested the questionnaires on $10 \%$ of the sampled pregnant women of the kersa district, that were not included in the main study, and modification was done based on the pre-test observations. The supervisors kept the alleyway of the field procedures and checked the completed questionnaires daily to approve the accuracy of data collected, and the research team managed the overall work of data collection.

\section{Data processing and analysis}

Data were double entered using EPiData version 3.1 software. Data were cleaned, coded, and checked for missing and outliers, for further analysis exported to STATA version 14 (College Station, Texas 77,845 USA) statistical software. The outcome variable was dichotomized as dietary practice $=1$ (appropriate) and dietary practice $=0$ (inappropriate). Thus, the Poisson 
regression analysis model with robust variance estimate was fitted to identify predictors of the dietary practice of women. For multivariable analyses, only variables that displayed a $p<0.25$ in the bivariate analyses were entered in the adjusted model. The backward regression was fitted with selected socio-economic and fertility-related variables. The results are presented as adjusted prevalence ratios (APRs) with 95\% CI. The statistical level of significance was set at alpha $=5 \%$. The explanatory variables were examined for multi-collinearity before taking them into multivariable models using correlation matrix for the regression coefficients, using the standard errors, and variance inflation factor value. Possible interactions between covariates were tested. Akaike's information criterion (AIC) and Bayesian information criterion (BIC) were used to test for model fitness.

To estimate the economic level of the families, a wealth index was employed. The wealth dispersion was generated by applying principal component analysis. The index was calculated based on the ownership of latrine, selected household asset, quantity of livestock, and source of water used for drinking, that was to 41 household variables (Supplementary file 1). Nutritional knowledge of the women was gauged through 16 nutritional knowledge questions on the feature of nutrition needed in their course of pregnancy. Lastly, the highest tertile was defined as having "Good" nutritional knowledge and the two lower tertiles were labeled as "Poor" nutritional knowledge. The maternal attitude was evaluated with 12 Likert scale questions using PCA. The factor scores were totaled and classified into tertiles (three parts), and the highest tertile was defined as having a "Favorable" maternal attitude and the two lower tertiles were characterized as "Unfavorable" maternal attitude. The maternal perceived vulnerability of malnutrition was evaluated with 10 Likert scale questions using PCA. The factor scores were totaled and classified into tertiles (three parts), and the highest tertile was defined as having a perceived vulnerability "Yes" and the two lower tertiles were characterized as "No" maternal perceived vulnerability. Similarly, perceived severity of malnutrition, perceived benefit to healthy nutrition perceived barrier to healthy nutrition and perceived self-efficacy to control malnutrition during pregnancy were calculated by using their composite questions. Women's autonomy was evaluated by seven validated questions which were adopted from the Ethiopian demographic health survey [22]. For each response to a question, the response to each question was coded as "one" when the decision was made by the pregnant women alone or jointly with their husband, otherwise "zero".

\section{Ethical consideration}

All methods of this study were carried out in accordance with the Declaration of Helsinki-Ethical principle for medical research involving human subjects. Ethical approval letter was obtained from Haramaya University Institutional Research Ethics and Review Committee (IRERC) with a reference number of (IHRERC/266/2020) before the commencement of data collection. Written informed consent to participate was obtained from participants and legally authorized representatives "of minors below 16 years of age and illiterates" and their privacy and confidentiality were maintained. All personal identifiers were excluded, and data was kept confidential and used for the proposed study only.

\section{Operational definition \\ Meal frequency}

Is defined as how many times a day peoples eat or several daily eating occasions.

\section{Appropriate dietary practices}

When women had at least four meals daily, good FVS, high DDS, and high ASF consumption, whereas it was inappropriate when women had less than four meals daily or Low FVS or low DDS or low ASF consumption $[6,23]$.

\section{Wealth index quintile}

Was computed from the wealth score of the households by PCA and the composite was ranked by quantile. Quintile was used to label the household's wealth status to poorest, poor, middle, rich, and richest category.

\section{Results}

\section{Socio-demographic characteristics}

A total of 475 pregnant women were eligible, 448 consented, making a response rate of $94.3 \%$. The mean age of the women was $25.68(+5.1)$, ranging from 16 to 36 . The majority of the respondents could not read or write (73.88\%), were housewives (96.1\%), farmers (93\%), and had a family size of $1-5$ (76.56\%). Only $20.09 \%$ of the respondents were in the richest quintiles, Table 1.

\section{Prevalence of dietary practice}

From the total respondents, 29.46\% (25-34\%), 37.5\% mean $( \pm S D)(9.03 \pm 2.79)$ and $24.78 \%(2-29 \%)$ of them had high dietary diversity, high food variety score and high consumption of animal source food, respectively. The prevalence of the appropriate dietary practice of pregnant women in the present study was $15.2 \%$ (95\% $\mathrm{CI}=11.96-18.84)$, Table 2 . Considering the consumption of the main food groups cereals $(100 \%)$, other vitamin A-rich fruits and vegetables (96.43\%), and pulses and nuts (53.35\%) constitute a major part of women's 
Table 1 Socio-demographic of pregnant women in Haramaya District, eastern Ethiopia, $2021(n=448)$

\begin{tabular}{|c|c|c|}
\hline Variables & Frequency(n) & Percentage (\%) \\
\hline \multicolumn{3}{|l|}{ Age (years) } \\
\hline$<18$ & 25 & 5.58 \\
\hline $18-35$ & 400 & 89.29 \\
\hline$>35$ & 23 & 5.13 \\
\hline Mean $( \pm S D)$ & $25.68( \pm 5.16)$ & \\
\hline \multicolumn{3}{|l|}{ Educational level of the woman } \\
\hline Can't read or write & 331 & 73.88 \\
\hline Read or write & 26 & 5.81 \\
\hline Formal education & 91 & 20.31 \\
\hline Educational Level of husband & & $49(23.33)$ \\
\hline Can't read or write & 259 & 57.81 \\
\hline Read or write & 61 & 13.62 \\
\hline Grade 1-8 & 102 & 22.77 \\
\hline Grade 9 and above & 26 & 5.8 \\
\hline \multicolumn{3}{|l|}{ Occupation of the woman } \\
\hline Housewives & 433 & 96.65 \\
\hline Merchants & 15 & 3.65 \\
\hline \multicolumn{3}{|l|}{ Occupation of husband } \\
\hline Farmers & 420 & 93.75 \\
\hline Daily labors & 28 & 6.25 \\
\hline \multicolumn{3}{|l|}{ Family size } \\
\hline $1-5$ & 343 & 76.56 \\
\hline$\geq 5$ & 105 & 23.44 \\
\hline \multicolumn{3}{|l|}{ Agricultural land possession } \\
\hline No & 271 & 60.49 \\
\hline Yes & 177 & 39.51 \\
\hline \multicolumn{3}{|l|}{ Livestock possession } \\
\hline Yes & 299 & 66.74 \\
\hline No & 149 & 33.26 \\
\hline \multicolumn{3}{|l|}{ Wealth Index (Quintile) } \\
\hline Poorest & 90 & 20.09 \\
\hline Poor & 90 & 20.09 \\
\hline Middle & 89 & 19.87 \\
\hline Rich & 90 & 20.09 \\
\hline Richest & 89 & 19.87 \\
\hline \multicolumn{3}{|l|}{ Parity } \\
\hline 0 & 103 & 22.99 \\
\hline $1-4$ & 294 & 65.63 \\
\hline$\geq 5$ & 51 & 11.38 \\
\hline
\end{tabular}

diet. Consumption of other fruits (1.7\%) was minimal. Figure 1.This monotonous diet may reflect both their cultural eating habits and lower availability of a variety of foods during the survey period.

\section{Factors associated with dietary practice}

In the bi-variable analysis, husband's educational level, woman's occupational status, ANC visit, perceived
Table 2 Dietary practices of pregnant women in Haramaya district, eastern Ethiopia,2021

\begin{tabular}{|c|c|c|}
\hline Variables & Frequency(n) & Percentage (\%) \\
\hline \multicolumn{3}{|c|}{ Dietary Diversity Score (DDS) } \\
\hline Low & 316 & 70.54 \\
\hline High & 132 & 29.46 \\
\hline Mean $( \pm S D)$ & $3.73( \pm 1.33)$ & \\
\hline \multicolumn{3}{|c|}{ Food Variety Sore (FVS) } \\
\hline Low & 280 & 62.50 \\
\hline High & 168 & 37.50 \\
\hline Mean $( \pm S D)$ & $9.03( \pm 2.80)$ & \\
\hline \multicolumn{3}{|c|}{ Animal Source Foods (ASFs) } \\
\hline Low & 337 & 75.22 \\
\hline High & 111 & 24.78 \\
\hline Mean $( \pm S D)$ & $25.68( \pm 5.16)$ & \\
\hline \multicolumn{3}{|l|}{ Meal frequency } \\
\hline$<4$ & 331 & 73.88 \\
\hline$\geq 4$ & 117 & 26.12 \\
\hline Mean $( \pm S D)$ & $2.98( \pm 0.84)$ & \\
\hline \multicolumn{3}{|l|}{ Dietary practice } \\
\hline Appropriate & 433 & 96.65 \\
\hline Inappropriate & 15 & 3.65 \\
\hline
\end{tabular}

venerability to malnutrition, perceived severity to malnutrition, perceived benefit to healthy nutrition, khat chewing, food restriction and food aversion (strong disliked of foods) were found to be a candidate for multivariable analysis at $p<0.25$. Level of appropriate dietary practice was higher among respondent who were merchant women $(\mathrm{APR}=2.07 ; 95 \% \mathrm{CI}=1.07-4.02)$, those whose husbands had at least high school educational level $(\mathrm{APR}=1.96 ; 95 \% \mathrm{CI}=1.06-3.46)$. However, level of appropriate dietary practice was significantly lower among those who reported chewing khat $(\mathrm{APR}=0.58$; $95 \% \mathrm{CI}=0.37-0.90)$ and restrict food taking during pregnancy $(\mathrm{APR}=0.36 ; 95 \% \mathrm{CI}=0.20-0.65)$, Table 3 .

\section{Discussion}

In the current study, the level of appropriate dietary practice among pregnant women was $15.18 \%$ and was noted to be sub-optimal. Moreover, women's occupational status, husband's educational level, chewing chat, and restriction of the intake of some foods were identified as predictors of dietary practice in Haramaya District. Adequate nutrition during pregnancy is essential for maternal and child health [3]. There is mounting evidence that insufficient consumption of a balanced and quality diet during pregnancy significantly affects fetus health and development and may result in poor birth outcomes [4]. At the beginning of pregnancy, many women lack 


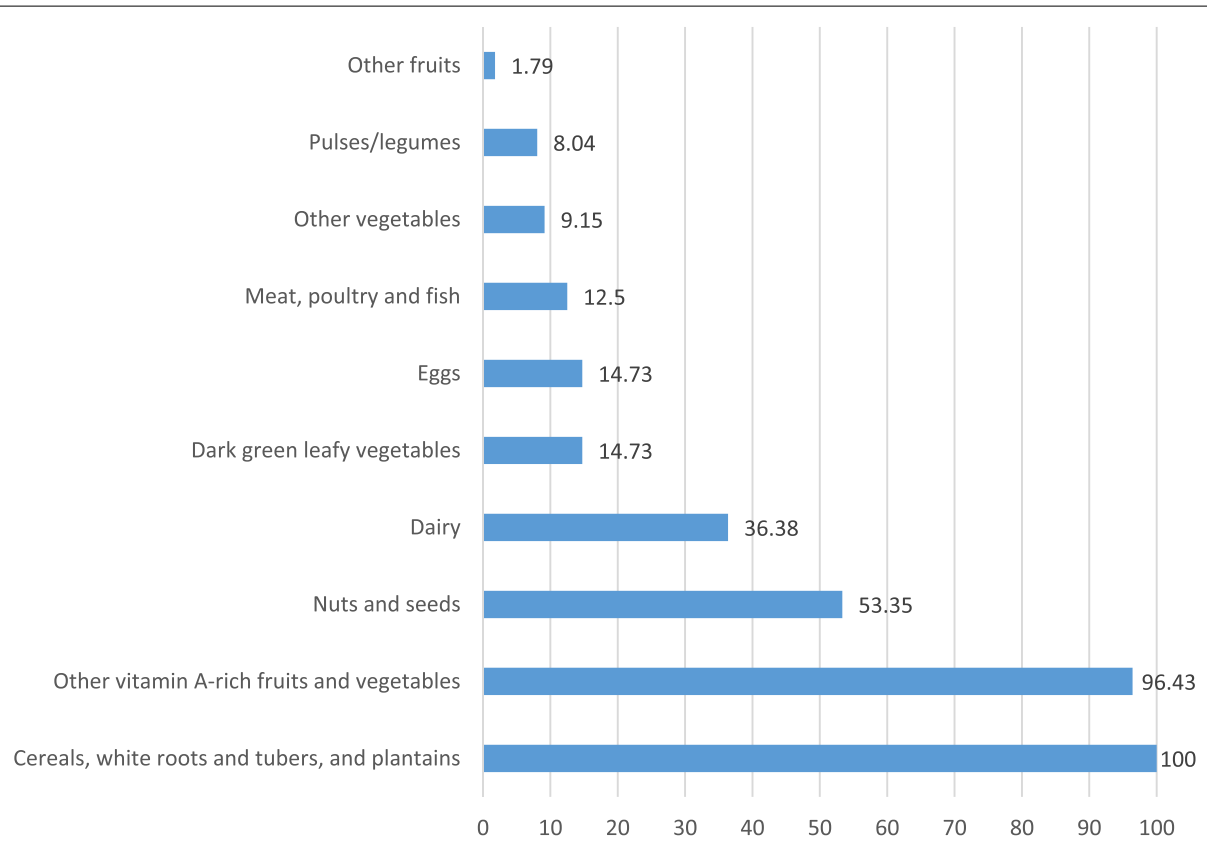

Fig. 1 Percentage of different food groups consumed by pregnant women in Haramaya District, Eastern Ethiopia,2021

sufficient micronutrient stores to meet the increased physiological requirements [1], and they are more vulnerable to malnutrition [26]. Several epidemiological studies indicated that inappropriate dietary practice contributes to maternal undernutrition and micronutrient deficiency in resource-limited countries $[9,25]$. Pregnant women's diet must supply adequate nutrients for the mother, fetus and effective lactation. Despite this reality, in this present study, noted appropriate dietary practice among pregnant women was very low. This figure was much lower than studies conducted in Illu Aba Bor Zone, Southwest Ethiopia [27], Dessie town, northeastern Ethiopia [28], and Guto Gida district, western Ethiopia [29]. The result of this study has modest deference to a study conducted in Gojjam in northwest Ethiopia (19.9\%) [6], which was carried out in a similar setup/rural residents. However, due to the differences in the study area and socio-cultural conditions, it is noteworthy to mention that the direct comparison of our results with previous investigations employed in Ethiopia is impossible. Furthermore, the possible reason for the discrepancy might be due to the difference in methods and measures applied to assess dietary practice since this study used four measures; DDS, FVS, consumption of ASF, and frequency of meals over 1 week. However, most of the previous studies carried out in Ethiopia used meal frequency to evaluate the dietary practice of pregnant women, which could not comprehensively assess dietary practices.
Dietary diversity is correlated with the probability of nutrient adequacy, increased nutrient intake, and better nutritional status of pregnant women [30]. Evidence suggested that consumption of animal source foods guarantees the intake of micronutrients among pregnant women in developing countries [24, 31]. Although consumption of animal source food has a significant share of dietary quality, the practice decreases in low-income counties [25]. We observed that only $29.46 \%$ of pregnant women have a high dietary diversity score in the present study. However, $37.5 \%$ of participants have a high mean food variety score. Furthermore, $24.78 \%$ of the women consumed animal source foods 1 week before the survey. The current dietary diversity in pregnancy is lower than various studies conducted in Ethiopia [5, 29, 32, 33] but higher than the study carried out in Shashemane town, central Ethiopia [11].

Similar to reports from Shashamane [11] and Egypt [34], our results also found that the occupational status of pregnant women had a significant association with dietary practice. Pregnant women who were merchants had higher dietary practices. Housewives are more confined to household work and financially dependent on their family and partners than those merchants [35]. This could be because women who participated in yielding their family financial income have a better chance of earning income and better access to diversified foods and appropriate diets. This suggests that a program to improve women's nutrition would be strengthened by increasing 
Table 3 Factors associated with dietary practice among pregnant women in Haramaya district, eastern Ethiopia, 2021

\begin{tabular}{|c|c|c|c|c|c|}
\hline \multirow[t]{2}{*}{ Variables } & \multicolumn{2}{|c|}{ Dietary Practice } & \multirow[t]{2}{*}{ CPR $(95 \% \mathrm{Cl})$} & \multirow[t]{2}{*}{ APR $(95 \% \mathrm{Cl})$} & \multirow[t]{2}{*}{$P$-value } \\
\hline & $\begin{array}{l}\text { Appropriate } \\
(n=68)\end{array}$ & $\begin{array}{l}\text { Inappropriate } \\
(n=380)\end{array}$ & & & \\
\hline \multicolumn{6}{|c|}{ Educational Level of Husband } \\
\hline Illiterate & $33(48.53)$ & $287(75.53)$ & 1 & 1 & \\
\hline Elementary School & $26(38)$ & $76(20.00)$ & $2.47(1.554,3.929)$ & $1.99(1.214,3.280)$ & $0.006^{*}$ \\
\hline High school and above & $9(13.24)$ & $17(4.47)$ & $3.37(1.806,6.239)$ & $1.92(1.063,3.460)$ & \\
\hline \multicolumn{6}{|c|}{ Occupational status of Women } \\
\hline Housewives & $61(89.71)$ & $372(97.89)$ & 1 & 1 & \\
\hline Merchants & $7(10.29)$ & $8(2.11)$ & $3.31(1.837,5.973)$ & $2.07(1.071,4.016)$ & $0.030^{*}$ \\
\hline \multicolumn{6}{|l|}{ ANC visit } \\
\hline No & $17(25.00)$ & $147(38.6)$ & 1 & 1 & \\
\hline Yes & $51(75.00)$ & $233(61.32)$ & $1.73(1.035,2.898)$ & $1.36(0.776,2.394)$ & 0.281 \\
\hline \multicolumn{6}{|l|}{ Perceived Venerability } \\
\hline No & $18(26.47$ & $(67(17.63)$ & 1 & 1 & \\
\hline yes & $50(73.53)$ & $313(82.37)$ & $1.54(0.947,2.496)$ & $0.82(0.4691 .428$ & 0.481 \\
\hline \multicolumn{6}{|l|}{ Perceived severity } \\
\hline No & $47(69.12)$ & $313(82.37)$ & 1 & 1 & \\
\hline Yes & $21(30.88)$ & $67(17.63)$ & $1.83(1.155,2.892)$ & $1.31(0.7472 .303)$ & 0.346 \\
\hline \multicolumn{6}{|l|}{ Perceived Benefit } \\
\hline No & $39(57.35)$ & $288(75.79)$ & 1 & 1 & \\
\hline Yes & $29(42.65)$ & $92(24.21)$ & $2.01(1.302,3.099)$ & $1.39(0.811,2.412)$ & 0.228 \\
\hline \multicolumn{6}{|l|}{ Chat chewing } \\
\hline No & $38(55.88)$ & $142(37.37)$ & 1 & 1 & \\
\hline Yes & $30(44.12)$ & $238(62.63)$ & $0.53(0.341,0.824)$ & $0.58(0.370,0.901)$ & 0.016 \\
\hline \multicolumn{6}{|l|}{ Drinking water } \\
\hline Protected & $42(61.76)$ & $156(41.05)$ & 1 & 1 & \\
\hline Unprotected & $26(38.24)$ & $224(58.95)$ & $0.49(0.312,0.771)$ & $0.61(0.350,1.048)$ & 0.073 \\
\hline \multicolumn{6}{|l|}{ Food restriction } \\
\hline No & $53(77.94)$ & $246(64.74)$ & & & \\
\hline Yes & $15(22.06$ & $134(35.26)$ & $0.57(0.331,0.974)$ & $0.36(0.200,0.651)$ & $0.001^{* *}$ \\
\hline \multicolumn{6}{|c|}{ Food aversion (Strong disliked of foods) } \\
\hline No & $47(69.12)$ & $267(70.26)$ & 1 & 1 & \\
\hline yes & $21(30.88)$ & $113(29.74)$ & $0.96(0.594,1.533)$ & $0.99(0.631,1.554)$ & 0.967 \\
\hline
\end{tabular}

Appropriate dietary practice: is defined as the consumption of at least four meals daily, high DDS, high FVS and high ASF; otherwise, Inappropriate dietary practice Drinking water sources: 'Protected' if tap/hand pump and not otherwise Elementary school: Grade 1-8

CPR Crude Prevalence Ration, APR Adjusted Prevalence Ratio, Cl Confidence Interval at 95\%

CPR: was obtained from bi-variate of Poisson regression analysis model with robust variance estimate

APR, $\mathrm{Cl}$ and $P$-Value were found from multivariable Poisson regression analysis model with robust variance estimate.

** statistically significant at $p$-value $<0.001,{ }^{*}$ statistically significant at $p$-value $<0.05$

women's involvement in family income generation, decision-making power, and economic independence.

The current study also revealed that women whose partners' education level of high school and above had higher appropriate dietary practice, which is consistent with the former studies done in Wachamo [36], and Shashamane [11]. This might be because literate partners have a better understanding of the importance of consuming a quality diet in pregnancy, and they may positively influence their wives to have appropriate dietary practices. Pregnant women who received dietary guidance are expected to consume a diversified diet compared to those who do not receive nutritional advice.

In this study, pregnant women who frequently avoided food intake were negatively associated with appropriate dietary practices, which is in line with a study carried out in Nepal [35], and China [37]. Pregnant women 
who practiced food avoidance have a higher odds of poor dietary practice. Our results indicated that the pattern of food avoidance could lead to a decline in dietary consumption and then micronutrient deficiency. The possible rationale of the deference might be mainly in the present study; most of the pregnant women who did avoid food intake did so in the third trimester of their pregnancy and at the time of interview.

Although chewing khat is an intensively disseminating act in Ethiopia and developed countries, comprising America and Europe [37-43], health consequences are well understood. The result of the current study highlights the importance of reducing the high level of inappropriate dietary practice during pregnancy with proper interventions. Therefore, pregnant women should frequently be advised of the negative consequences of chat chewing and supported to improve their dietary consumption in pregnancy.

The strengths of this study include the following: validated food frequency questionnaires were used to assess dietary practice, food items were established based on consultation of key informants from the study area who were knowledgeable about the culture, local language, and locally consumed foods. Various limitations to be considered when interpreting our results include the following: the cross-sectional nature of the data limits causal inference between dietary practice and their correspondences and dietary diversity and correlates, and due to sample collection being from a single season, this limits the generalizability of the results to other reasons. In addition, due to individual differences of dietary consumption in the study setup over 7 days, we establish our definition of the reference period of 7 days. Women who could have eaten food items more than one in 7 days were also tagged with those who consumed one time over 7 days could underrate the amount used up is another limitation.

\section{Conclusion}

The study showed that the dietary practice of pregnant women in the Haramaya district is sub-optimal. It can be concluded that greater access to resources through the involvement of women in yielding their family financial income, partners education, dietary restriction, and chewing chat, as gauged by the study, was noted to be significantly associated with dietary practice during pregnancy. Undesirable dietary habits and nutrition-related practices, which are often based on insufficient knowledge, traditions and taboos or poor understanding of the relationship between diet and health, can adversely affect nutritional status. Thus, we suggest that nutrition policy, programs, and interventions encourage prenatal dietary practice focusing on women's empowerment in generating their family income and raising partners' awareness of the benefit of the quality diet in pregnancy for mothers and newborns. Promoting husbands' engagement in providing continuous care in pregnancy should be tailored to meet the need of pregnant women and to improve their dietary practice. Social and behavioral change communication on maternal nutrition should promote shifts in social norms on food taboos using religious leaders and influential community members to realize adequate nutrition for pregnant women.

\section{Abbreviations \\ ANC: Antenatal Care; ASF: Animal Source Food; DDS: Dietary Diversity Score; EDHS: Ethiopian Demographic and Health Survey; FCS: Food Consumption Score; FVS: Food Variety Score; HDS-HRC: Health Demographic Surveillance and Health Research Center; PCA: Principal Component Analysis; WHO: World Health Organization.}

\section{Supplementary Information}

The online version contains supplementary material available at https://doi. org/10.1186/s40795-021-00494-4.

\section{Additional file 1.}

\section{Acknowledgments}

We would like to express our sincere appreciation to Haramaya University for funding this study. Special thanks go to the Haramaya district health office staff for their enormous support during the data collection period. Finally, we like to thank all the women who participated in the study, the data collectors, and supervisors.

\section{Authors' contributions}

All authors were involved in the conception, design of the study, and statistical analysis and result interpretation. MBF drafted the manuscript which was reviewed for intellectual content by KTR, LO, AKT and TAY. All authors read and approved the final version for submission and agreed to be accountable for all aspects of the article.

\section{Funding}

This study was funded by Haramaya University as part of a doctoral study by MBF. The funder has no role in the conception, design of the study, statistical analysis, result interpretation, manuscript writing, or the decision for publication.

\section{Availability of data and materials}

All data are availability within the manuscript. Additional data can be obtained from the corresponding author on a reasonable request.

\section{Declarations}

\section{Ethics approval and consent to participate}

All methods of this study were carried out in accordance with the Declaration of Helsinki-Ethical principle for medical research involving human subjects. Ethical approval letter was obtained from Haramaya University Institutional Research Ethics and Review Committee (IRERC) with a reference number of (IHRERC/266/2020) before the commencement of data collection. Written informed consent to participate was obtained from participants and legally authorized representatives "of minors below 16 years of age and illiterates" and their privacy and confidentiality were maintained. All personal identifiers were excluded, and data was kept confidential and used for the proposed study only.

Consent for publication

Not applicable. 


\section{Competing interests}

The authors declare no conflicts of interest in this work.

\section{Author details}

${ }^{1}$ Department of Public Health, Institute of Health Sciences, Wollega University, Nekemte, Ethiopia. ${ }^{2}$ School of Nursing and Midwifery, College of Health and Medical Sciences, Haramaya University, Harar, Ethiopia. ${ }^{3}$ Department of Obstetrics and Gynaecology, University Medical Centre Groningen, University of Groningen, Groningen, the Netherlands. ${ }^{4}$ School of Public Health, College of Health and Medical Sciences, Haramaya University, Harar, Ethiopia.

Received: 25 September 2021 Accepted: 22 December 2021

Published online: 11 January 2022

\section{References}

1. Kramer MS. Maternal nutrition, pregnancy outcome, and public health policy. Can Med Assoc J. 1998;159:663.

2. MAD FBP, Eundem FAD. Maternal Physiology. Dewhurst's Textbook of Obstetrics \& Gynaecology; 2012.

3. Kramer MS. Determinants of low birth weight: methodological assessment and meta-analysis. Bull World Health Organ. 1987;65:663.

4. Gogoi M, Prusty RK. Maternal anemia, pregnancy complications and birth outcome: evidences from north-East India. J North East India Stud. 2013;3:74-85

5. Alemayehu MS, Tesema EM. Dietary practice and associated factors among pregnant women in Gondar town north west, Ethiopia. Int J Nutr Food Sci. 2015;4:707-12

6. Demilew YM, Alene GD, Belachew T. Dietary practices and associated factors among pregnant women in west Gojjam zone, Northwest Ethiopia. BMC Pregnancy Childbirth. 2020;20:18.

7. Leyna GH, Mmbaga EJ, Mnyika KS, Hussain A, Klepp K-I. Food insecurity is associated with food consumption patterns and anthropometric measures but not serum micronutrient levels in adults in rural Tanzania. Public Health Nutr. 2010;13:1438-44.

8. Oldewage-Theron $\mathrm{WH}$, Egal AA. Nutrition knowledge and nutritional status of primary school children in QwaQwa. South Afr J Clin Nutr. 2010;23(3)

9. Lee SE, TalegawkaR SA, Merialdi M, Caulfield LE. Dietary intakes of women during pregnancy in low-and middle-income countries. Public Health Nutr. 2013:16:1340-135.

10. Lander RL, Hambidge KM, Westcott JE, Tejeda G, Diba TS, Mastiholi SC, et al. Pregnant women in four low-middle income countries have a high prevalence of inadequate dietary intakes that are improved by dietary diversity. Nutrients. 2019:11:1560.

11. Othoo D, Waudo J, Kuria E. Dietary assessment of vitamin A and Iron among pregnant women at Ndhiwa Sub District Hospital-Kenya. Afr J Food Agric Nutr Dev. 2014;14:2114-28.

12. Kennedy G, Fanou-fogny N, Seghieri C, Arimond M, Koreissi Y, Dossa R, et al. Food groups associated with a composite measure of probability of adequate intake of 11 micronutrients in the diets of women in urban Mali. J Nutr. 2010;140:2070S-8S.

13. Kennedy GL, Pedro MR, Seghieri C, Nantel G, Brouwer I. Dietary diversity score is a useful indicator of micronutrient intake in non-breast-feeding Filipino children. J Nutr. 2007;137:472-7.

14. Ogle BM, Hung PH, Tuyet HT. Significance of wild vegetables in micronutrient intakes of women in Vietnam: an analysis of food variety. Asia Pac J Clin Nutr. 2001;10:21-30.

15. HOP, L. T. Programs to improve production and consumption of animal source foods and malnutrition in Vietnam. J Nutr. 2003;133:4006S-9S.

16. Marshall TA, Stumbo PJ, Warren JJ, Xie X-J. Inadequate nutrient intakes are common and are associated with low diet variety in rural, communitydwelling elderly. J Nutr. 2001;131:2192-6.

17. Neumann C, HARRIS DM. Contribution of animal source foods in improving diet quality for children in the developing world; 1995.

18. Lindsay K, Gibney E, Mcauliffe F. Maternal nutrition among women from sub-Saharan Africa, with a focus on Nigeria, and potential implications for pregnancy outcomes among immigrant populations in developed countries. J Hum Nutr Diet. 2012;25:534-46 Haramya District health office.
Annual report of Haramya district health office Haramya, Eastern Ethiopia; 2020.

19. Nana A, Zema T. Dietary practices and associated factors during pregnancy in northwestern Ethiopia. BMC Pregnancy Childbirth. 2018;18:183.

20. Kennedy G, Ballard T, Dop MC. Guidelines for measuring household and individual dietary diversity, Food and Agriculture Organization of the United Nation; 2011.

21. ALLEN, L. H. Interventions for micronutrient deficiency control in developing countries: past, present and future. J Nutr. 2003;133:3875S-8S.

22. Belachew T, Lindstrom D, Gebremariam A, Hogan D, Lachat C, Huybregts $L$, et al. Food insecurity, food based coping strategies and suboptimal dietary practices of adolescents in Jimma zone Southwest Ethiopia. PLoS One. 2013:8:e57643.

23. Gebreyesus SH, Lunde T, Mariam DH, Woldehanna T, Lindtjørn B. Is the adapted household food insecurity access scale (HFIAS) developed internationally to measure food insecurity valid in urban and rural households of Ethiopia? BMC Nutrition. 2015;1:1-10.

24. Workicho A, Belachew T, Feyissa GT, Wondafrash B, Lachat C, Verstraeten $\mathrm{R}$, et al. Household dietary diversity and animal source food consumption in Ethiopia: evidence from the 2011 welfare monitoring survey. BMC Public Health. 2011;16:1-11.

25. Torheim LE, Barikmo I, Parr CL, Hatløy A, Ouattara F, Oshaug A. Validation of food variety as an indicator of diet quality assessed with a food frequency questionnaire for Western Mali. Eur J Clin Nutr. 2003;57:1283-91.

26. Kant AK, Thompson FE. Measures of overall diet quality from a food frequency questionnaire: National Health Interview Survey, 1992. Nutr Res. 1992:17:1443-56.

27. Central statistical agency( CSA)(Ethiopia) and ICF. Ethiopia demographic and health survey Addis Ababa and Rockville: CSA and ICF; 2016.

28. Sukrat B. Thailand adolescent birth rate: trend and related indicators. Thai J Obstet Gynaecol. 2014:15-21.

29. Hoffmann JF, Nunes MAA, Schmidt MI, Olinto MTA, Melere C, Ozcariz SGl, et al. Dietary patterns during pregnancy and the association with sociodemographic characteristics among women attending general practices in southern Brazil: the ECCAGe study. Cadernos de saude publica. 2013;29:970-80.

30. Tsegaye D, Tamiru D, Belachew T. Factors associated with dietary practice and nutritional status of pregnant women in rural communities of Illu aba Bor zone, Southwest Ethiopia. Nutr Dietary Suppl. 2020;12:103-12.

31. Daba G, Beyene F, Fekadu H, Garoma W. Assessment of knowledge of pregnant mothers on maternal nutrition and associated factors in Guto Gida Woreda, east Wollega zone, Ethiopia. J Nutr Food Sci. 2013:3:1.

32. Mirmiran P, Esmaillzadeh A, Azizi F. Detection of cardiovascular risk factors by anthropometric measures in Tehranian adults: receiver operating characteristic (ROC) curve analysis. Eur J Clin Nutr. 2004;58:1110-8.

33. Steyn NP, Nel JH, Nantel G, Kennedy G, Labadarios D. Food variety and dietary diversity scores in children: are they good indicators of dietary adequacy? Public Health Nutr. 2006;9:644-50.

34. Speedy AW. Global production and consumption of animal source foods. J Nutr. 2003;133:4048S-53S

35. Desta M, Akibu M, Tadese M, Tesfaye M. Dietary diversity and associated factors among pregnant women attending antenatal clinic in Shashemane, Oromia, Central Ethiopia: a cross-sectional study. J Nutr Metab. 2019;2019. https://doi.org/10.1155/2019/3916864.

36. Alkalash $\mathrm{SH}$, Hegazy NN, Elnady RT, Khalil NA. Dietary practice and nutritional status among pregnant women. The Egyptian Journal of Hospital Medicine. 2021;83:1030-7.

37. Shrestha V, Paudel R, Sunuwar DR, Lyman ALT, Manohar S, Amatya A. Factors associated with dietary diversity among pregnant women in the western hill region of Nepal: A community based cross-sectional study. PLoS One. 2021;16:e0247085.

38. Delil $\mathrm{R}$, Zinab B, Mosa H, Ahmed R, Hassen $\mathrm{H}$. Determinants of dietary diversity practice among pregnant women attending antenatal clinic at Wachemo University Nigist Eleni Mohammed memorial referral hospital, Southern Ethiopia. PloS One. 2021;16:e0250037.

39. Lamina S. Khat (Catha edulis): the herb with officio-legal, socio-cultural and economic uncertainty. South Afr J Sci. 2010;106(3):1-4.

40. Gao H, Stiller CK, Scherbaum V, Biesalski HK, Wang Q, Hormann E, et al. Dietary intake and food habits of pregnant women residing in urban and rural areas of Deyang City, Sichuan Province, China. Nutrients. 2013:5:2933-54. 
41. Gebissa E. Khat in the horn of Africa: historical perspectives and current trends. J Ethnopharmacol. 2010;132:607-14.

42. Griffiths P, Lopez D, Sedefov R, Gallegos A, Hughes B, Noor A, et al. Khat use and monitoring drug use in Europe: the current situation and issues for the future. J Ethnopharmacol. 2010;132:578-83.

43. Odenwald M, Warfa N, Bhui K, Elbert T. The stimulant khat-another door in the wall? A call for overcoming the barriers. J Ethnopharmacol. 2010;132:615-9.

\section{Publisher's Note}

Springer Nature remains neutral with regard to jurisdictional claims in published maps and institutional affiliations.

- fast, convenient online submission

- thorough peer review by experienced researchers in your field

- rapid publication on acceptance

- support for research data, including large and complex data types

- gold Open Access which fosters wider collaboration and increased citations

- maximum visibility for your research: over $100 \mathrm{M}$ website views per year

At BMC, research is always in progress.

Learn more biomedcentral.com/submissions 